\title{
Prevalence of Systemic Hypertension in Students Aged 7 to 14 Years in the Municipality of Barbacena, in the State of Minas Gerais, in 1999
}

\author{
Dilermando Fazito de Rezende, Ricardo Augusto Baêta Scarpelli, Guenael Freire de Souza, \\ José Orleans da Costa, Adelaide Maria Baêta Scarpelli, Paulo Antônio Scarpelli, \\ Guilherme Bahia de Carvalho, Hélius Moreira D’Agostini, Josuela Cabral Pedrosa
}

Barbacena, MG - Brazil

\begin{abstract}
Objective - To detect the prevalence of systemic hypertension in children and to establish the relation between blood pressure levels and sex, age, ethnicity, weight, and height.
\end{abstract}

Methods - The prevalence of systemic hypertension and its relation to sex, age, ethnicity, weight, and height were studied in 611 students aged 7 to 14 years out of 19.928 students classified according to age, ethnicity, and sex, who underwent anthropometric evaluation and blood pressure measurement. Hypertensive individuals were considered those whose blood pressure level was $\geq$ the 95 th percentile for age and sex, confirmed on 3 examinations.

Results - The prevalence of hypertension was $16.6 \%$ in the first evaluation, and $4.6 \%$ and $2.5 \%$ in the subsequent evaluations. The mean blood pressure levels increased with age. Weight was important, not only to determine blood pressure in healthy children, but also to determine systemic hypertension in children, which was not observed with height despite the different studies. The prevalence of systemic hypertension in the differentethnic groups and the mean blood pressure levels according to sex were similar.

Conclusion - In addition to routine physical examinations, age, weight, and appropriate cuff size should be considered when assessing blood pressure in children to prevent hypertension, morbidity and mortality, and to avoid placing a financial burden on health care providers.

Key words: hypertension, children, epidemiology

Faculdade de Medicina de Barbacena, MG

Mailing address: Ricardo B. Scarpelli - Pça Pres. Antônio Carlos, 25 - Cep 36202-336 Barbacena, MG, Brazil - E-mail: rabscarpelli@yahoo.com.br

English version by Stela Maris C. e Gandour
Adult arterial hypertension is a well-defined condition with well-established parameters of normality ${ }^{1,2}$. In pediatric patients, however, information is less abundant ${ }^{3,4}$. The prevalence of systemic hypertension in the adult population is extremely high, ranging from 10 to $30 \%{ }^{5-7}$, and, in children, it ranges from 1 to $11 \%^{1,6,8-11}$.

In adults, arterial hypertension is the second risk factor for heart disease and the first for cerebral stroke, in addition to being an important cause of end chronic renal failure ${ }^{5,7,12}$. Evidence exists that the natural history of adult essential hypertension begins in childhood ${ }^{3-6,8,10-17}$. Despite this evidence, in medical practice, measurement of blood pressure in children and adolescents is usually delayed, preventing the early detection of the problem and its subsequent treatment ${ }^{14}$. In the national literature, only 6 studies on the prevalence of arterial hypertension in children were found ${ }^{5,8,13,14,18,19}$.

For a long period of time, secondary arterial hypertension was believed to predominate in children ${ }^{4,16}$. In reality, the diagnosis was only established when the disease was accompanied by severe symptoms or when the pressure levels were very high ${ }^{4,16}$. Children with mild or moderate systemic hypertension, usually cases of essential hypertension, passed undiagnosed due to the lack of routine examinations ${ }^{13,16}$.

Several factors have been correlated with blood pressure levels, the major being socioeconomic level, ethnicity, dietary habits, age, wakefulness and sleep, familial aggregation, weight, and height $t^{6,15,16,18}$. The adequate characterization of these factors should be the preoccupation of those aiming at preventing the damage related to systemic arterial hypertension. The identification of the frequency of this entity, mainly among the young, may help in the primary prevention of a series of cardiovascular, neurological, and renal complications, in addition to favoring the 
prognosis of the disease, the increase in the patients' survival, and the reduction in the costs of public and private health care ${ }^{3,15}$.

The present study aimed at determining the prevalence of arterial hypertension in children aged 7 to 14 years in the city of Barbacena, in the state of Minas Gerais, and at examining the possible correlations between blood pressure and hypothetically influential factors, such as weight, age, height, sex, and ethnicity

\section{Methods}

A cross-sectional study was carried out with data obtained in an inquiry about systemic arterial hypertension in students aged 7 to 14 years in the city of Barbacena, in the state of Minas Gerais, in 1999. Of the 19.928 students registered in elementary and middle schools, 649 were selected for the study through simple random sampling. Forty-two were excluded from the study because either their parents did not allow their children to undergo blood pressure examination or the students were out of the specified age group. The inquiry was based on contact with the children selected and performance of a succinct physical examination, with obtainment of information about age, sex, skin color, weight, height, and blood pressure level.

The study comprised blood pressure measurements on 3 distinct occasions: the first, measurement of blood pressure in the 607 children; the second, measurement of blood pressure exclusively in the participants considered hypertensive on the first measurement; the third, blood pressure measurements in those who remained hypertensive in the second phase of the inquiry.

Blood pressure was measured on the right arm with the child seated after a 3-to-5-minute rest, with the arm at the same level as the precordium. Aneroid sphygmomanometers were used. A cuff appropriate for the dimensions of the arm was chosen as follows: the cuff should occupy two thirds or more of the arm length leaving the antecubital fossa free, and the cuff's length should be long enough to surround the arm. The sphygmomanometers were previously calibrated against a pneumatic system with a mechanical regulator certified by the Brazilian Institute of Weights and Measurements (Instituto de Pesos e Medidas - INMETRO), and the zero level of the devices was assessed daily during the inquiry.

At the first blood pressure measurement, sometimes a borderline or short cuff was used, mainly for children aged 7 to 9 years, despite observance of the cited rules. On the 2 subsequent measurements, longer cuffs were chosen, still observing the criteria adopted.

Three blood pressure measurements at 2-minute intervals were taken on each occasion. Initially, the palpation method was used, followed by 2 measurements using the auscultatory method with the cuff inflated $20 \mathrm{mmHg}$ above the systolic pressure level found on the first measurement. The complete disappearance of heart sounds (phase V) was considered the diastolic blood pres sure level. When this phase did not exist, the reduction in the intensity of heart sounds (phase IV) was adopted as the reference. The final estimate was the lowest value of the 3 blood pressure measurements.

The reference values for detecting normal or elevated blood pressure were those of the Task Force graph ${ }^{3,15,17}$. Pressure levels equal to or above the 95 th percentile for each age and sex were considered altered, and patients with these levels were classified as hypertensive. This was the criterion adopted to characterize the normotensive or hypertensive patients identified in each phase of the inquiry.

The second and third examinations comprised only blood pressure measurements taken under the same conditions as the first measurement and with the same examiner. The longest cuff for the child's arm was used on these 2 occasions aiming at avoiding false-positive results.

Data obtained on the examinations were recorded on forms specifically designed for the study and later transferred to magnetic medium for computer analysis. This analysis was performed with EPI-INFO version 6.04 and STATA 7.0 Softwares. The distributions of frequency of the variables on the forms were constructed, and the prevalence rates were calculated in the usual manner. The subgroups of the sample were compared using contingency tables of the $\mathrm{RxC}$ type for categorical variables and using means and their respective standard errors for data expressed on a numeric scale. In these comparisons, the differences were tested using the chi-square test, the Student $t$ test, and the F test in ANOVA tables. The Student curve was used for calculating the confidence intervals. To analyze the relationship between the participant's clinical status (hypertensive or normotensive) and weight, height, or ethnicity, logistic regression models with step-by-step entry and removal of variables were used. The variables age and sex were excluded from the analysis because they were used in the clinical status classification (hypertensive or normotensive) on the Task Force graphs ${ }^{3,15,17}$. The likelihood of inclusion was 0.10 and the likelihood of exclusion was 0.15 . To assess the adequacy of the model, the Hosmer-Lemeshow goodnessof-fit test was used, whilst the chi-square test for logistic regression was used for verifying the overall significance of the effects of the variables included in the models.

Studying the relation of systolic and diastolic blood pres sure levels with the other variables, multiple linear regression models with step-by-step entry and removal of variables were used, with the samelikelihood of inclusion and exclu sion applied to the logistic regression. In this study, the same participant was examined more than once in the 3 phases of the inquiry and the last blood pressure level recorded for each child was used as the dependent variable in the analysismo dels. The level of statistical significance adopted in the comparisons and for calculating the intervals was $5 \%$.

\section{Results}

In the study, the 607 students enrolled underwent the first examination of the inquiry. The children considered 
hypertensive on that occasion (101 children) were reexamined in the second phase. Of the latter, only 28 children remained with high blood pressure levels, undergoing then the third examination.

The mean age of the students was $10.9(\mathrm{SD}=2.3)$ years. In regard to sex, the sample comprised 313 females $(51.6 \%)$ and 294 males (48.4\%). In regard to ethnicity, 404 were white $(66.6 \%), 149$ were mulattos $(24.5 \%), 53$ were black $(8.7 \%)$, and 1 was of far eastern heritage $(0.2 \%)$. The mean height of the students was $1.44(\mathrm{SD}=0.14)$ meters, the minimum and maximum heights being $1.13 \mathrm{~m}$ and $1.84 \mathrm{~m}$, respectively. The mean weight of the children was $37.3(\mathrm{SD}=12.6)$ $\mathrm{kg}$, the minimum and maximum weights being $11 \mathrm{~kg}$ and 85 $\mathrm{kg}$, respectively.

The prevalence of systemic arterial hypertension among the participants in the 3 blood pressure measurements is shown in table I.

The mean systolic and diastolic blood pressure levels of the children considered hypertensive and normotensive in each phase of blood pressure measurement are shown in table II. The latter table also shows the mean systolic and diastolic blood pressure levels obtained in the last examination of each participant according to the clinical status determined in the third phase. The mean systolic and diastolic blood pressure levels of the normotensive and hypertensive children according to sex and ethnicity are also shown. The blood pressure values according to sex and skin color shown in table II were obtained on the occasion of the last blood pressure measurement.

Studying the relation between the participants' clinical status and the other variables recorded, the classification performed at the end of the third phase revealed 11 (3.5\%) and 4(1.4\%) hypertensive females and males, respectively. The comparison of these 2 percentages had a chisquare $\left(\mathrm{x}^{2}\right)$ of 2.918 and $\mathrm{P}=0.09$. The relation between the same variable and the participants' ethnicity showed that 11 white children $(2.7 \%)$, 1 mulatto child $(0.7 \%)$, and 3 black children $(5.7 \%)$ were hypertensive. The simultaneous comparison of the 3 percentages had an $\mathrm{x}^{2}$ of 4.339 and $\mathrm{P}=0.11$. The mean ages of the normotensive and hypertensive students were, respectively, $10.9 \pm 2.3$ and $12.3 \pm 1.8$ years. The mean weights of the normotensive and hypertensive children were, respectively, $36.9 \pm 12.4 \mathrm{~kg}$ and $53.1 \pm 12 \mathrm{~kg}$. On the other hand, the mean heights of the normotensive children and children considered hypertensive were, respectively, $1.44 \pm 0.14 \mathrm{~m}$ and $1.56 \pm 0.1 \mathrm{~m}$
The relation between clinical status and these variables was tested with the logistic regression model. The odds ratios (OR) obtained in the model for the variables sex, skin color, age, and height had confidence intervals with lower limits $<1$ and upper limits $>1$. Weight was the only variable with a value different from this pattern: $\mathrm{OR}=1.089, \mathrm{Z}=4.455$, and $\mathrm{P}<0.0001$. The Hosmer-Lemeshow goodness-of-fit test was 5.25 with $\mathrm{P}=0.73$.

The comparison of the mean systolic and diastolic blood pressure levels of male and female normotensive students, shown in table II, revealed $\mathrm{t}=1.330$ and $\mathrm{P}=0.183$, and $\mathrm{t}=0.173$ and $\mathrm{P}=0.87$, respectively. This same comparison among the hypertensive students revealed $t=1.145$ and $\mathrm{P}=0.27$ for the systolic means and $\mathrm{t}=1.364$ and $\mathrm{P}=0.20$ for the diastolic means. The results of the comparison of the mean systolic and diastolic blood pressure levels obtained using the ANOVA table for the 3 skin color groups were as follows: in normotensive students: $\mathrm{t}=0.949$ and $\mathrm{P}=0.41$ for the mean systolic blood pressure levels, and $t=0.721$ and $\mathrm{P}=0.59$ for the mean diastolic blood pressure levels; and in hypertensive students: $\mathrm{t}=1.162$ and $\mathrm{P}=0.30$ for the mean systolic blood pressure levels, and $\mathrm{t}=0.447$ and $\mathrm{P}=0.82$ for the mean diastolic blood pressure levels.

The coefficients of linear regression of weight, height, and age obtained in a model of multiple linear regression in the study of the relation between these variables and systolic and diastolic blood pressure levels in hypertensive and normotensive children are shown in table III. In normotensive children, the results of the tests of regression models in regard to the above-cited variables in ANOVA tables were $\mathrm{F}=101.85$ and $\mathrm{P}<0.0001$ for systolic blood pressure, and $\mathrm{F}=40.18$ and $\mathrm{P}<0.0001$ for diastolic blood pressure. The $r^{2}$ values observed in the 2 models were 0.3423 and 0.1661 , respectively. In hypertensive children, the results of the equivalent tests of regression models were as follows: $\mathrm{F}=1.20$ and $\mathrm{P}=0.36$ for systolic blood pressure, and $\mathrm{F}=0.63$ and $\mathrm{P}=0.61$ for diastolic blood pressure.

\section{Discussion}

In our sample, the female and male percentages were almost the same with a slight difference favoring females. These percentages and those regarding ethnicity may be a reliable reflex of the demographic pattern of the municipality investigated, but noother statistics regarding ethnicity and sex of the students in Barbacena were found for comparison.

\begin{tabular}{|c|c|c|c|c|c|c|}
\hline \multirow[t]{2}{*}{ Clinical classification } & \multicolumn{2}{|c|}{$1^{\text {st }}$ exam } & \multicolumn{2}{|c|}{$2^{\text {nd }}$ exam } & \multicolumn{2}{|c|}{$3^{\text {rd }}$ exam } \\
\hline & $\mathrm{n}$ & $\%$ & $\mathrm{n}$ & $\%$ & $\mathrm{n}$ & $\%$ \\
\hline Normotensive & 506 & 83.4 & 579 & 95.4 & 592 & 97.5 \\
\hline Hypertensive & 101 & 16.6 & 28 & 4.6 & 15 & 2.5 \\
\hline Isolated systolic hypertension & 38 & 6.3 & 15 & 2.5 & 8 & 1.3 \\
\hline Isolated diastolic hypertension & 26 & 4.3 & 4 & 0.7 & 3 & 0.5 \\
\hline Systo-diastolic hypertension & 37 & 6.1 & 9 & 1.5 & 4 & 0.7 \\
\hline
\end{tabular}




\begin{tabular}{|c|c|c|c|c|}
\hline \multicolumn{5}{|c|}{$\begin{array}{c}\text { Table II - Mean systolic and diastolic blood pressure (BP), standard } \\
\text { deviations (SD), and sample sizes according to the participants' } \\
\text { clinical status and data classification criteria }\end{array}$} \\
\hline \multirow[t]{2}{*}{ Class of data } & \multicolumn{2}{|c|}{ Systolic levels } & \multicolumn{2}{|c|}{ Diastolic levels } \\
\hline & Normotensive & Hypertensive & Normotensive & Hypertensive \\
\hline \multicolumn{5}{|l|}{$1^{\text {st }}$ exam } \\
\hline Mean \pm SD & $108.3 \pm 12$ & $129.3 \pm 11.8$ & $66.5 \pm 9.8$ & $83.3 \pm 10.9$ \\
\hline $\mathrm{N}$ & 506 & 101 & 506 & 101 \\
\hline \multicolumn{5}{|l|}{$2^{\text {nd }}$ exam } \\
\hline Mean \pm SD & $99 \pm 13.9$ & $138.9 \pm 11.2$ & $62.3 \pm 11$ & $82.1 \pm 12.7$ \\
\hline $\mathrm{N}$ & 73 & 28 & 73 & 28 \\
\hline \multicolumn{5}{|l|}{$3^{\text {rd }}$ exam } \\
\hline Mean \pm SD & $116.9 \pm 9.3$ & $140.7 \pm 14.3$ & $73.1 \pm 9$ & $82.7 \pm 12.9$ \\
\hline $\mathrm{N}$ & 13 & 15 & 13 & 15 \\
\hline \multicolumn{5}{|c|}{ Last BP measurement } \\
\hline Mean \pm SD & $107.4 \pm 12.7$ & $140.7 \pm 14.3$ & $66.2 \pm 10$ & $82.7 \pm 12.9$ \\
\hline $\mathrm{N}$ & 592 & 15 & 592 & 15 \\
\hline \multicolumn{5}{|l|}{ Male } \\
\hline Mean \pm SD & $106.6 \pm 12.5$ & $133.7 \pm 18$ & $66.1 \pm 10.1$ & $90 \pm 8.2$ \\
\hline $\mathrm{N}$ & 290 & 4 & 290 & 4 \\
\hline \multicolumn{5}{|l|}{ Female } \\
\hline Mean \pm SD & $108 \pm 12.9$ & $143.2 \pm 12.7$ & $66.2 \pm 10$ & $80 \pm 13.6$ \\
\hline $\mathrm{N}$ & 302 & 11 & 302 & 11 \\
\hline \multicolumn{5}{|l|}{ Skin color } \\
\hline \multicolumn{5}{|l|}{ White } \\
\hline Mean & $107.4 \pm 12.7$ & $138.6 \pm 13.4$ & $65.9 \pm 10.1$ & $82.7 \pm 12.1$ \\
\hline $\mathrm{N}$ & 393 & 11 & 393 & 11 \\
\hline \multicolumn{5}{|l|}{ Mulatto } \\
\hline Mean & $106.5 \pm 12.6$ & $130 \pm 0$ & $66.6 \pm 9.5$ & $90 \pm 0$ \\
\hline $\mathrm{N}$ & 148 & 1 & 148 & 1 \\
\hline \multicolumn{5}{|l|}{ Black } \\
\hline Mean & $109.3 \pm 13.2$ & $151.7 \pm 16.1$ & $67.1 \pm 10.9$ & $80 \pm 20$ \\
\hline $\mathrm{N}$ & 50 & 3 & 50 & 3 \\
\hline
\end{tabular}

In our study, the prevalence of systemic hypertension among the students corresponds to the number of hypertensive children found on the third examination (tab. I), which was $2.5 \%$ of the examinees. Unfortunately, no record of previous studies on the prevalence of systemic hypertension in Barbacena exists, which prevents an assessment of the evolution of that parameter over time.

The variation in the frequency of arterial hypertension observed in different studies is no surprise, because neither the groups studied (sample selection, technique used, age group, ethnicity), nor the methodology used was similar ${ }^{5,9,11,13,14,20,21}$. It is worth emphasizing that some studies performed only 1 measurement, while others did
2. Considering the instability of blood pressure in children, the lowest value of 3 successive blood pressure measurements on different visits is recommended as the final estimate prior to defining the actual blood pressure value $^{3-7,10,11,13,17}$. Therefore, the prevalence of hypertension in childhood decreased between the first and the third visit, from $13 \%$ to $1 \%$ in the Muscatine Study and from $9 \%$ to $2 \%$ in the Dallas Study ${ }^{9,13,20,21}$. In our study, this fact was also observed, and the prevalence dropped from $16.6 \%$ to $2.5 \%$.

In the Belo Horizonte study ${ }^{14}$, the prevalence found with the second blood pressure measurement was very similar to that found in the same phase of the present study, although the prevalences found on the first blood pressure measurement in the 2 studies were very different. The prevalence of $2.5 \%$ found in Barbacena was one third of that found in the studies carried out in São Paulo and Botucatu. This difference in prevalence may be due to methodological differences, because no objective reason exists to believe that the populations of these cities are very different ${ }^{13}$. On the other hand, the comparison with international studies has shown that the prevalence found in Barbacena is close to that found in the Dallas and Iowa studies ${ }^{9,20,21}$.

If the values obtained in this study are correct, one may conclude that the prevalence of systemic hypertension was relatively low in the area studied, although they suggest the existence of approximately 500 hypertensive children in the population studied.

According to that which was expected, a drop in the number of hypertensive patients occurred in the different phases of the study, being greater in the transition from the first to the second phase, probably due to the change in the size of the cuff used for measuring blood pressure from the second phase onwards.

The recording of the mean systolic and diastolic blood pressure levels (tab. II) in each phase of the study shows a gradual and persistent increase in systolic blood pressure from one phase to the other and stable diastolic blood pressure values of approximately $82 \mathrm{~mm} \mathrm{Hg}$ in the 3 phases. This fact is in accordance with the idea that false hypertensive individuals are withdrawn from the group in subsequent phases of blood pressure measurement. The recordings of systolic and diastolic blood pressure levels in normotensive individuals have different patterns of varia-

\begin{tabular}{|c|c|c|c|c|c|c|}
\hline \multirow[t]{2}{*}{ Variable } & \multicolumn{3}{|c|}{ SBP } & \multicolumn{3}{|c|}{ DBP } \\
\hline & Coefficient & Minimum & Maximum & Coefficient & Minimum & Maximum \\
\hline \multicolumn{7}{|c|}{ Normotensive } \\
\hline Age & 1.20 & 0.48 & 1.92 & 0.84 & 0.20 & 1.48 \\
\hline Weight & 0.41 & 0.28 & 0.54 & 0.24 & 0.12 & 0.35 \\
\hline Height & 0.59 & -13.98 & 15.15 & -3.13 & -16.01 & 9.76 \\
\hline \multicolumn{7}{|c|}{ Hypertensive } \\
\hline Age & -0.17 & -6.70 & 6.35 & 2.77 & -3.54 & 9.07 \\
\hline Weight & -0.13 & -1.08 & 0.82 & -0.29 & -1.20 & 0.63 \\
\hline Height & 86.30 & -67.08 & 239.68 & 5.39 & -142.78 & 153.56 \\
\hline
\end{tabular}


tion. The mean systolic and diastolic blood pressure levels decreased from the first to the second examination and increased again in the third phase. Because a more appropriate cuff was used on the second visit, the reduction in the mean blood pressure levels on the second visit may be attributed to this change in the procedure. The possible inappropriate selection of the cuff for some children (most aged 7 to 9 years), occurred when the device selected was borderline or short for the arm's size. Short cuffs tend to increase blood pressure ${ }^{1,3,7,12,17}$. Voors et $\mathrm{al}^{22}$, in the Bogalusa Heart Study, also reported relatively elevated mean blood pressure levels in children aged 5 and 6 years, which was attributed to improper cuff selection. Brandão et $\mathrm{al}^{5}$, in a study carried out in the city of Rio de Janeiro, found elevated mean blood pressure levels in children aged 6 to 9 years, suggesting that the anxiety and fear observed in that population increased blood pressure values. In the present study, this fact was also observed, perhaps because most of the children had never undergone blood pressure measurement before.

Table II also shows that the blood pressure levels of the normotensive individuals with the third measurement were much greater than those in the first and second phases. As these children were considered hypertensive in the first phase of the study, they may represent the group of children with high normal blood pressure. Obviously, the mean blood pressure levels of the hypertensive individuals were greater than those of the normotensive individuals.

Studying the relation between clinical status and the variables sex, skin color, and age, the statistical tests performed and their results indicate, either on univariate or multivariate analysis, that no valid statistical relation exists between these variables and the chances that the children are hypertensive or normotensive. On the other hand, an OR of 1.089 , relative to weight and adjusted to the effects of the other variables, indicates that the chance of the students being hypertensive or not relates to weight, and this relation does not depend on the other variables studied.

In normotensive individuals, the study of the relation between systolic and diastolic blood pressure levels and the same variables (tab. III) indicates that sex, ethnicity, and height seem not to correlate with blood pressure levels. The coefficients of regression for weight $(0.41$ for systolic blood pressure and 0.24 for diastolic blood pressure) and age (1.20 for systolic blood pressure and 0.84 for diastolic blood pressure) suggest that blood pressure levels in this group of children bear a direct relation with these variables. The attempt to assess the relations between blood pressure levels and those variables among hypertensive children showed coefficients of regression statistically indistinct from zero for all factors included in the models of analysis; therefore, no relation between blood pressure and weight, height, age, sex, or ethnicity could be demonstrated in this group. Among hypertensive individuals, the attempt to demonstrate a relation between blood pressure levels and weight was unsuccessful probably due to the small number of children with systemic hypertension studied.

In the Muscatine Study, more than half of the children with persistent hypertension were obese ${ }^{9,21}$. In the city of Botucatu $^{6}$, the prevalence of systemic hypertension in big or macrosomic (heavy and tall) children, who accounted for $6.14 \%$ of the sample, was $29.5 \%$, whilst in the general pediatric population that prevalence was $7.05 \%{ }^{13}$. A direct correlation between weight and blood pressure levels has been reported from the age of 5 years, being more prominent in the second decade of life ${ }^{15}$. The results of the present study suggest that weight is important, not only in determining blood pressure levels in healthy children but also in determining systemic hypertension as a disease in children.

In our study, height did not correlate with either clinical status or blood pressure levels; on the other hand, Sinaiko ${ }^{15}$ reported a correlation between elevated height and elevated mean blood pressure in all ages. The study from Botucatu also showed a strong correlation between height and blood pressure ${ }^{13}$. The French school has adopted height as one of the references for the diagnosis of systemic hypertension in children ${ }^{6,13}$. The different methodologies used in the different studies are worth noting, because the statistical treatment applied to data from the present study may be a source of dis crepancy with that mentioned in the literature. In some studies, height may not have been analyzed as a variable dissociated from overweight and age, confounding the results. The fact that height relates to weight generates difficulties in as sessing its importance in determining blood pressure values. Nevertheless, weight may be the mostimportantisolated risk factor for hypertension among children ${ }^{3,6,11-13,15,17,21}$.

The studies are controversial in regard to the relation between blood pressure and systemic hypertension with skin color ${ }^{6,8,11}$. Sinaiko ${ }^{15}$ and Brandão et al $^{5}$ identified no association between blood pressure and ethnicity among children. In the present study, no relation between persistent hypertension and skin color was observed, as was no association of blood pressure levels with that variable. Rosa and Ribeiro $^{8}$, Bastos et $\mathrm{al}^{6,13}$, and Voors et $\mathrm{al}^{22}$, in the Bogalusa Heart Study, reported a positive association between the black race and elevated blood pressure levels. The racial mixture in our population may perhaps be an important factor in this relation, a factor that was not analyzed in our study.

According to Shalma et al ${ }^{12}$ and Sinaiko ${ }^{15}$, the clinical status of blood pressure is not significantly different between the sexes. The tables of blood pressure according to age provided by the Task Force do not differ for boys and girls ${ }^{3,17}$, and these observations were confirmed in our study.

In our study, age was an important factor and was related to blood pressure levels, but this did not happen with clinical status. Voors et $\mathrm{al}^{22}$ reported that for each year of life an increase from 1.2 to $1.7 \mathrm{mmHg}$ occurs in systolic blood pressure and of $1 \mathrm{mmHg}$ in diastolic blood pressure. In the study from Santo André ${ }^{18}$, blood pressure increase was also observed with age. Bastos et al ${ }^{6}$ reported that blood pressure gradually increases with age in both sexes until growth is completed by the age of $18-20$ years. The portrayal of blood pressure related to age in percentage tables ${ }^{3,17}$ shows the dynamism of the phenomenon and the tendency of individuals to follow a certain blood pressure 
channel over time (tracking); this makes the follow-up of groups of children with potentially dangerous blood pressure levels from early ages until adulthood interesting ${ }^{16}$. The tendency of blood pressure to increase from birth is known, but the importance of age to blood pressure as an isolated factor is unknown. Although most epidemiological studies use normograms of sex and age to detect systemic hypertension in children, age may act as a confounding factor $3,4,6,8,10,15,17$. It is worth noting that variables, such as height and body weight, are directly proportional to age, which makes the study of that factor difficult. Rosa and Ribeiro ${ }^{8}$ suggest the controlled analysis of age to assess its actual importance.
Blood pressure levels should be measured in children and adolescents as part of a routine physical examination to prevent systemic hypertension and the morbidity and mortality of this affliction in that population, therefore avoiding imposing a financial burden on health care providers. Age, weight, and the use of an appropriate-sized cuff should be considered when assessing blood pressure in childhood. The disagreement between the results of the present study and those reported in the literature indicates the need for a review of the possible relations between clinical status and the child's height, mainly when considering the recommendation to use the second variable as an indicator of the risk of systemic hypertension in children.

\section{References}

1. Terceiro Consenso Brasileiro de Hipertensão Arterial. Rev Bras Cardiol 1999; 1: 96-131.

2. Schoen FJ. Vasos sanguíneos. In: Contran RS, Kumar V, Robbins SL (eds). Patologia Estrutural e Funcional. Rio de Janeiro: Guanabara Koogan; 1996.

3. Horan M, Falkner B, Sinaiko A, et al. Report of the Second Task Force on Blood Pressure Control in Children. Pediatrics 1987; 79: 1-25.

4. Silva ACS, Oliveira RG, Silva JMP, Monteiro JL. Hipertensão arterial. In: Leão E, Corrêa EJ, Viana MB, et al (eds). Pediatria Ambulatorial. Belo Horizonte: Coopmed; 1998.

5. Brandão AP, Ferreira JO, Brandão AA, Pozzan R, Cerqueira RCO. Avaliação da pressão arterial em crianças e adolescentes: estudo do Rio de Janeiro. Hiperativo 1996; 3: 87-92.

6. Bastos H, Macedo CS, Riyuso MC. Hipertensão arterial na criança. Rev Doenças Cardiovasc 1994; 35: 23-6.

7. Joint National Committee. The sixth report of the Joint National Committee on Detection, Evaluation and Treatment of High Blood Pressure. Arch Int Med 1997; 157: 2413-46.

8. Rosa AA, Ribeiro JP. Hipertensão arterial na infância e na adolescência: fatores determinantes. JPediatria 1999; 75:75-82

9. Rames LK, ClarkeWR, ConnorWE, ReiterMA,Lauer RM.Normal blood pressure elevation in childhood: the Muscatine Study. Pediatrics 1978;61:245-51.

10. Saldanha RV, Lima JJG, Neto JM. Hipertensão arterial sistêmica. In: Marcruz R, Snitowsky R (eds). Cardiologia Pediátrica. São Paulo: Sarvier, 1983.

11. Rachid J, Lima MP, Rachid MBF. Rastreamento da hipertensão arterial sistêmica nainfância. J Bras Med 1996; 70: 16-22

12. Shalma A, Sinaiko AR. Systemic hypertension. In: Emmanouilies G, Riemesch- neider T, Allen Het al (eds). Heart Disease in Infants, Children and Adolescents Including the Fetus and the Young Adults. Baltimore: Williams \& Wilkins; 1995.

13. Bastos HD, Macedo CS, Riyuso MC. Pressão arterial - conceito de normalidade. Pediatria Moderna 1993; 29: 223-37.

14. Oliveira RG, Lamounier JA, Oliveira ADB, Castro MDR, Oliveira JS. Pressão arterial em escolares e adolescentes - o estudo de Belo Horizonte. J Pediatria 1999; 75: 256-66.

15. Sinaiko AR. Hypertension in children. NEngl J Med 1996; 335: 1968-73.

16. FranscischettiEA, Fagundes VGA. A história natural da hipertensãoessencial começa na infância e adolescência? Hiperativo 1996; 3: 77-85.

17. Daniels SR, Falkner B, Rosner B, et al. Update on the 1987 Task Force report on high blood pressure in children and adolescents: a workgroup report from the National High Blood Pressure Education Program. Pediatrics 1998; 98: 649-58.

18. Viegas D, Mailho FL, Fukushima NM, Julio AG, Hata LA. Avaliação dos níveis pressóricos basais na cidade de Santo André. Pediatria Moderna 1993; 29:241-250.

19. Brasil. Ministério da Saúde. Saúde no Brasil. Ministério da Saúde: Brasília, 1997. [s.n.t.].

20. Fixler DE, Laird WP, Fitzgerald V, Stead S, Adams R. Hypertension screening in schools: results of the Dallas Study. Pediatrics 1979; 63:32-6.

21. Lauer RM, Burns TL, Clarke WR. Assessing children's blood pressure-Considerations of age and body size:the Muscatine Study. Pediatrics 1985; 75: 1081-90.

22. Voors AW, Foster TA, Frerichs RR, Webber LS, Berenson GS. Studies of blood pressures in children, ages 5-14 years, in a total biracial community: the Bogalusa Heart Study. Circulation 1976; 54:319-326. 